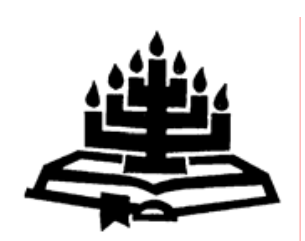

\title{
'n Toepaslike metafoorteorie vir die ontleding van metafore in die Nuwe Testament
}

\author{
H. Goede \\ Skool vir Bybelwetenskappe \& Antieke Tale \\ Fakulteit Teologie \\ Potchefstroomkampus \\ Noordwes-Universiteit \\ POTCHEFSTROOM \\ E-pos: Hennie.Goede@nwu.ac.za
}

\begin{abstract}
An appropriate theory of metaphor for the analysis of metaphors in the New Testament
\end{abstract}

The aim of this article is to identify a theory of metaphor that is appropriate for the interpretation of the metaphors in the New Testament. The many metaphors in the New Testament force the exegete to properly account for the nature of metaphor and its contribution to the transmission of the message. An appropriate theory of metaphor must also properly account for the unique nature of the Bible and the New Testament as part of it. Different theories of metaphor are considered and criteria for the selection of a suitable theory stated. On the basis of such criteria, a selection of an appropriate theory of metaphor will be made, and the selected theory will be described in detail.

\section{Opsomming}

'n Toepaslike metafoorteorie vir die ontleding van metafore in die Nuwe Testament

Die doel van hierdie artikel is om 'n toepaslike metafoorteorie vir die interpretasie van die metafore in die Nuwe Testament te identifiseer. Die talle metafore in die Nuwe Testament dwing die eksegeet om die aard van 'n metafoor en die bydrae wat dit tot die oordra van die boodskap lewer, deeglik te verreken. Verder moet 'n toepaslike metafoorteorie ook die unieke aard van die Bybel en die Nuwe Testament as onderdeel daarvan verreken. Verskillende metafoorteorieë sal oorweeg word en kriteria vir die keuse van 'n toepaslike teorie sal gestel word. Op grond 
van hierdie kriteria sal 'n toepaslike metafoorteorie gekies word, en die gekose teorie sal in besonderhede beskryf word.

\section{Inleiding}

Die talle metafore wat in die Nuwe Testament voorkom, dwing die eksegeet om die aard van 'n metafoor en die bydrae wat dit tot die oordra van die boodskap lewer, deeglik te verreken. Verder moet die unieke aard van die Bybel en die Nuwe Testament as onderdeel daarvan, goed in enige metafoorteorie verreken word ten einde sodanige teorie bruikbaar vir die studie te maak.

Teoloë openbaar 'n vooroordeel ten gunste van die bestudering van metafore as blote literêre verskynsels, eerder as om die wetenskaplike gebruik van metafore in die teologie te bestudeer (Gunton, 1989:42). Hierdie vooroordeel lei tot 'n persepsie dat Bybelse metafore verbeeldingryke uitdrukkings van menslike ervaring van die wêreld is, eerder as 'n middel om uiting te gee aan die werklikheid van God. Die rede hiervoor is dat God in ' $n$ ander verband tot die menslike verstand staan as die natuur. Laasgenoemde kan, volgens die Kantiaanse model, deur die sintuie objektief benader word, maar vir eersgenoemde is een of ander vorm van subjektivisme nodig.

Hoewel 'n mens aanneem dat daar 'n kwalitatiewe verskil tussen die aardse en die goddelike is, kan die goddelike alleen in terme van die aardse deur aardse assosiasies en kategorieë beskryf word (Van der Watt, 2000:22). Indien 'n mens dus oor die goddelike wil praat, moet 'n mens dit in metafore doen. In hierdie verband tree metafore beskrywend en kreatief op. Metafore beskryf 'n werklikheid of saak op 'n nuwe manier wat nog nie voorheen gebruik is nie. Metafore kan egter ook nuwe werklikhede skep wat alleen op die vlak van taal bestaan. Metafore wat na die transendente wêreld verwys, doen tot 'n mate albei. Om te sê dat God 'n arm het, mag moontlik nie met die letterlike werklikheid ooreenstem nie, maar deur metafoor word 'n arm vir God "geskep" sodat die funksie wat menslikerwys met 'n arm geassosieer word, metafories met God geassosieer word (Van der Watt, 2000:23). So maak die mens sin van sy beperkte toegang tot die transendente werklikheid. Tog is dit ook beskrywend, want die werklikheid het reeds bestaan en is deur God so geopenbaar.

Die metafoor is dus 'n belangrike instrument in die literêre analise van die Nuwe Testament, en daarom moet die eksegeet 'n 
verantwoorde metafoorteorie gebruik om metafore mee te ontleed. Die doel van hierdie artikel ${ }^{1}$ is om 'n toepaslike metafoorteorie te vind wat by die interpretasie van die metafore in die Nuwe Testament gebruik kan word. In die gereformeerde tradisie sal 'n gepaste metafoorteorie ook gemaklik binne 'n grammaties-historiese eksegetiese benadering verreken moet kan word.

\section{Terminologie}

Verskillende outeurs gebruik in die bespreking van hulle metafoorteorieë dikwels verskillende terme vir dieselfde saak. Richards (1936:96) is die eerste linguis wat 'n tegniese onderskeid tussen die topiek of strekking (tenor) en medium (vehicle) van die metafoor tref. Strekking verwys na die normale betekenis binne die normale konteks, en medium verwys na die figuur wat van buite die normale konteks ingebring word (Richards, 1936:96-97). ${ }^{2}$ Die oordrag van die strekking wat deur middel van die medium plaasvind, is die metafoor. Strekking en medium is algemene en buigbare terme wat in hulleself sterk metafories is, en met betrekking tot die analise van metafore op verskillende wyses geïnterpreteer kan word. Die meeste navorsers volg hierdie onderskeid na, hoewel die terminologie mag verskil. Dit word by die beskrywing van elke teorie aangedui.

\section{Verskillende metafoorteorieë}

\subsection{Inleiding}

Stanford (1936:1) sê "a fine metaphor is one of the hardest things in the world to rationalize". Die waarheid van hierdie stelling blyk uit die uiteenlopende metafoorteorieë wat in die literatuur uiteengesit word. Tot relatief onlangs is ' $n$ metafoor deur die meeste navorsers as ' $n$ linguistiese eienaardigheid beskou, as "fancy language" wat deur digters, politici, ensovoorts gebruik word (Steen, 1994:3). Tog blyk dit uit die literatuur dat daar 'n progressie van denke oor metafore was. Hierdie progressie kan soos volg opgesom word:

- Die tradisionele beskouing is dat metaforiese betekenis 'n semantiese fenomeen is (Cooper, 1986:46). Dit beteken dat

1 Verwerking van 'n hoofstuk uit die outeur se M.A.-verhandeling (Goede, 2004).

2 In die metafoor "the man is a wolf", is "the man" die strekking en "wolf" die medium (Van der Watt, 2000:18). 
elemente van taal soos woorde of sinne, afgesien van hulle letterlike betekenisse, ook metaforiese betekenisse kan hê.

- Die standaardsiening (in 1986) is egter dat metaforiese betekenis die bedoeling van die spreker/outeur is, aangesien dit nie inherent aan woorde of sinne is nie (Cooper, 1986:66). Wat 'n spreker/outeur bedoel, is nie altyd identies aan die voor die hand liggende betekenis van die sin nie.

- 'n Derde beskouing is dat metaforiese betekenis nie in die taal of die spreker/outeur gewortel is nie (Cooper, 1986:89). lets soos metaforiese betekenis bestaan eenvoudig nie, aangesien die metafoor nie meer kognitiewe inhoud as die letterlike oordra nie.

- 'n Vierde beskouing is dat 'n metafoor nie in die eerste plek beeldspraak (figure of speech) is nie, maar ideëspraak (figure of thought) (Steen, 1994:6). 'n Metafoor is fundamenteel die oorneem van gedagtes, 'n oordrag tussen kontekste (Richards, 1936:94). Die mens se gewone konseptuele stelsel in terme waarvan 'n mens sowel dink as handel, is fundamenteel metafories van aard (Lakoff \& Johnson, 1980:3).

Binne hierdie breë raamwerk het baie teorieë oor die interpretasie van metafore met die verloop van tyd ontwikkel. Enkele van hierdie teorieë word vervolgens kortliks getipeer in die proses om die teorieë te weeg met die oog op toepaslikheid vir die bestudering van die metafore van die Nuwe Testament.

\subsection{Interaksieteorie}

Die interaksieteorie (interaction theory) erken dat daar twee onderskeie subjekte is, naamlik die topiek en die medium, en dat die metaforiese uiting sekere eienskappe van die medium op die topiek projekteer (Goatly, 1997:117). Hierdie eienskappe is die grond vir die interpretasie ("grounds of interpretation") en is gebaseer op ooreenkoms of analogie tussen die medium en die topiek.

Kittay (1987:13) noem hierdie teorie 'n perspektiwiese teorie ("perspectival theory") op grond van die funksie wat 'n metafoor vervul, naamlik om 'n perspektief te verskaf waaruit 'n begrip van dit wat metafories voorgestel word, verkry kan word. Perspektief beskryf die tipe interaksie wat tussen die topiek en die medium plaasvind (dus die grond vir die interpretasie). Hierdie beskouing sluit aan by die kognitiewe teorie (sien 3.10 hieronder), maar verskil ook daarvan in die sin dat op die linguistiese eerder as op die kognitiewe gefokus word. 


\subsection{Spannings- of weersprekingsteorie}

Die interaksieteorie is die grondslag vir die spannings- of weersprekingsteorie ("tension theory") (Goatly, 1997:118). Die spanningsteorie beklemtoon dat die belangrikste effek van 'n metafoor die emosionele of logiese spanning is wat deur semantiese teenstrydigheid veroorsaak word. Die basiese uitgangspunt is dat een of ander vorm van semantiese spanning tussen die medium en die topiek tot 'n nuwe betekenis van die medium lei (Bouson, 1980:70-71). Die diskoerseenheid moet metafories in terme van die nuwe betekenis geïnterpreteer word ten einde absurditeit te vermy.

\subsection{Vergelykingsteorie gebaseer op betekenisverandering}

In hierdie vorm van die vergelykingsteorie ("comparison theory") is daar slegs sprake van ' $n$ vergelyking tussen A en B (Bouson, 1980:72). 'n Betekenisverandering vind plaas op grond van die resultate van sodanige vergelyking. Die netto effek is dat $A$ in sekere opsigte $B$ is. Die opsigte waarin A dan B is, word deur die konteks bepaal (Bouson, 1980:78).

\subsection{Vergelykingteorie nie gebaseer op betekenisverandering nie}

As sodanig stel die vergelykingsteorie ("comparison theory") dat die metafoor ten beste beskou moet word as 'n elliptiese of onvolledige weergawe van 'n vergelyking (Goatly, 1997:118). Daar is vir elke metafoor 'n geassosieerde vergelyking, sodat die metafoor en vergelyking dieselfde betekenis het (Bouson, 1980:39). As die metafoor sê: $A$ is $B$, sal die vergelyking sê: $A$ is soos $B$. Dit beteken nie dat ' $n$ vergelyking dieselfde tipe effek as sy ekwivalente metafoor het nie, maar eerder dat die vergelyking en metafoor wat interpretasie betref, ekwivalent is (Goatly, 1997:118).

Hierdie teorie behels twee stappe, naamlik die reduksie van die metafoor tot 'n vergelyking en die samesmelting van 'n figuurlike en letterlike vergelyking ("simile and literal comparison") (Tirrell, 1991:337). Dit staan ook as die klassieke vergelykingsteorie of reduktiewe vergelykingsteorie ("reductive simile theory of metaphor") bekend.

\subsection{Plaasvervangingsteorie}

Die plaasvervangingsteorie ("substitution theory") stel dat die medium in die plek van 'n letterlike term staan; dat die betekenis van die metafoor bepaal kan word deur die letterlike term in die plek van 
die medium te plaas, en dat 'n metafoor daarom 'n dekoratiewe middel is (Goatly, 1997:116).

\subsection{Gevoelsteorie}

Die emotiewe of gevoelsteorie ("emotive theory") stel dat 'n metafoor 'n uitdrukking met emosionele impak is, maar sonder enige betekenis (Bouson, 1980:84). Die individuele woorde mag betekenis hê, maar die kombinasie nie, omdat dit nie geverifieer kan word nie.

\subsection{Fenomenalistiese teorie}

Die fenomenalistiese teorie ("phenomenalistic theory") maak 'n onderskeid tussen normale prosatekste en poëtiese tekste (Bouson, 1980:87). In sogenaamde normale tekste word 'n vorm van plaasvervanging toegepas, maar in poëtiese tekste word metafore sonder meer as onwerklik beskou.

\subsection{Die twee-stap-model}

Volgens die twee-stap-model ("two-step model") word metafore twee keer geïnterpreteer: eers letterlik en dan figuurlik of metafories (Tourangeau, 1982:20). Die grondslag van dié model is dat die interpretasie van 'n metafoor deur een of ander anomalie aan die gang gesit word. Die tweede stap vind plaas omdat die eerste tot 'n vreemde of irrelevante letterlike interpretasie aanleiding gee. Die inhoud van die tweede stap is om die eienskappe geassosieer met die topiek en medium met mekaar te probeer versoen.

\subsection{Kognitiewe teorie van metafoor}

Vir die meeste mense is 'n metafoor 'n middel van poëtiese verbeelding en retoriese welsprekendheid (Lakoff \& Johnson, 1980:3). 'n Metafoor is 'n saak van buitengewone eerder as gewone taal, van woorde eerder as gedagtes of dade. Die kognitiewe teorie van metafoor ("cognitive theory of metaphor") stel egter dat die mens se gewone konseptuele stelsel in terme waarvan die mens dink én handel, fundamenteel metafories van aard is (Lakoff \& Johnson, 1980:3). Daarom beteken metafoor eintlik konsep. Hierdie konsepte is integraal deel van die konseptuele sisteem van elke kultuur waarin die mees fundamentele waardes van daardie kultuur vervat is. Lakoff en Johnson (1980) se aanvanklike hipotese is met verloop van tyd deur die bevindings van die kognitiewe linguistiek bevestig (Liebenberg, 2001:76). 
Die essensie van 'n metafoor is om een ding in terme van 'n ander te verstaan en te ervaar (Lakoff \& Johnson, 1980:5). Dit geskied deur die kartering (mapping) van een konseptuele domein na 'n ander (Lakoff \& Turner, 1989:112). 'n Metafoor is dus struktureel gesproke kognisie. Die metafoor fokus die aandag op een aspek van 'n konsep, en terselfdertyd draai dit die fokus weg van ander aspekte wat teenstrydig met die metafoor is. Metafore skep ook ooreenkomste (Lakoff \& Johnson, 1980:153). Dit staan in kontras met die vergelykingsteorie wat beweer dat metafore bloot reedsbestaande ooreenkomste beskryf.

Lakoff en Johnson (2002:253) gebruik die term konseptuele metafoor (conceptual metaphor) as 'n basiese vooronderstellende insig of intuïsie wat 'n hele teorie fundeer. Mac Cormac (1985:19) verwys hierna as 'n basiese metafoor ("basic metaphor"). Konseptuele metafore het hoogs konvensioneel geword tot die punt waar daar nie meer iets innoverend of afwykend aan hulle is nie. Hierdie konvensionele konseptuele metafore is deel van die algemene kennis van die gebruiker van taal, en word as konseptuele eenhede in die verstand gestoor.

Dit volg dat die verbale aspek van 'n metafoor as afhanklik of afgelei van die konseptuele metafoor beskou moet word. Lakoff en Johnson (2002:253) gebruik die term linguistiese metafoor (linguistic metaphor) om die verbale manifestasies van die konseptuele metafoor te beskryf. 'n Konseptuele metafoor kan homself in verskeie grammatikale variasies (werkwoord, naamwoord, idiomatiese uitdrukkings, ensovoorts) deur verskillende leksikale items of retoriese middels (soos allegorie, metafoor, vergelyking, en so meer) manifesteer. Die konseptuele grondslag bly dieselfde, maar die linguistiese manifestasie verskil.

\subsection{Semantiese veld-teorie}

Die semantiese veld-metafoorteorie ("semantic field theory of metaphor") is 'n poging om die kognitiewe krag van 'n metafoor in terme van semantiese veld-teorie te verstaan (Steinhart \& Kittay, 1994:41 e.v.). Semantiese veld-teorie assimileer die konseptuele struktuur tot 'n semantiese struktuur wat menslike uiting fundeer. Die betekenis van ' $n$ woord is volgens hierdie teorie gedeeltelik 'n funksie van sy verhouding tot woorde wat dieselfde konseptuele terrein betrek. Die teorie stel dat die leksikon georganiseer is volgens konseptuele affiniteite en kontraste, soos gereflekteer in die semantiese verhoudings wat velde struktureer. Die teorie sluit ook analogiese beredenering in, aangesien analogie as onderliggend tot 
die kognitiewe prosesse in die produksie van metaforiese uitings beskou word (Steinhart \& Kittay, 1994:43). In metaforiese taal skep analogie verbande tussen semantiese velde wat andersins nie in verband met mekaar staan nie.

\subsection{2 'n Interaktiewe teorie van kognisie en metafoor}

Indurkhya (1994:95) stel 'n interaktiewe teorie van kognisie en metafoor ("interaction theory of cognition and metaphor") voor. Hy gebruik die terme teiken (target) vir die objek wat deur die metafoor beskryf word en bron (source) vir die objek wat gebruik word om die teiken te beskryf. Hy tref 'n onderskeid tussen die ontologie en die struktuur van die wêreld (Indurkhya, 1994:106). Ontologie is die stel objekte of handelinge in terme waarvan die mens die wêreld ervaar of daarop reageer. Struktuur is die interafhanklikheid tussen die objekte en handelinge. Die ontologie word geskep deur die kognitiewe agent, maar die struktuur is onafhanklik van die agent en afhanklik van die eksterne werklikheid. Die ervaringswêreld is dus gelyk geskep deur en onafhanklik van die agent. Die ooreenkomste wat metafore skep, is die resultaat van die interaksie tussen ontologie en struktuur.

\subsection{Van der Watt se metafoorteorie}

Van der Watt (2000:6) se teorie is gebaseer op 'n funksionele beskrywing van metafoor. Die funksie van 'n metafoor is om uit bestaande betekenisse van twee leksikale items 'n nuwe betekenis te vorm. Hierdie oordrag van betekenis gebeur wanneer dit wat gesê word, deur een of ander vorm van identifikasie of vergelyking gekoppel word aan dit wat bedoel word. Analogie staan hier sterk op die voorgrond. 'n Metafoor kom tot stand wanneer die letterlike betekenis van die woord in 'n sin absurd, irrelevant of onwaar is, hoewel die sin nogtans 'n nuttige inhoud kan hê (Van der Watt, 2000:7). Onverenigbaarheid (incongruency) op sintaktiese en semantiese vlak speel dus hier 'n belangrike rol. Die eerste lees verwys die leser terug na die semantiese bevoegdheid van die woord om vir alternatiewe betekenisse te soek. Volgens Van der Watt lê metaforiese betekenis in die onkonvensionele eerder as die konvensionele. In hierdie opsig sluit hy dus by die interaksieteorie, weersprekingsteorie en die twee-stap-model aan. Metaforiese kommunikasie is dus oop kommunikasie; dit skep die potensiaal vir nuwe betekenis (Van der Watt, 2000:13). 


\subsection{Samevatting}

Ek meen dat daar in etlike van bogenoemde teorieë bruikbare elemente lê. Die kognitiewe teorie beskryf na my mening ten beste die plek van die metafoor in taal as refleksie van die werklikheid. Dat 'n metafoor elemente van plaasvervanging en vergelyking bevat, is ook waar. In 'n sekere sin ly al die teorieë egter aan eensydigheid. In elk geval, min van dié teorieë (en die voorstanders daarvan) volg die teorie op met 'n metodiek vir die toepassing daarvan. ${ }^{3}$

\section{Kriteria vir die bepaling van 'n geskikte metafoorteorie}

\subsection{Aard van metafoor: tradisionele beskouing teenoor kognisie}

Volgens die tradisionele beskouing is 'n metafoor ' $n$ middel vir gebruik in poëtiese verbeelding en retoriese uitdrukking (Lakoff \& Johnson, 1980:3). Die mens kan hiervolgens gemaklik sonder 'n metafoor regkom, aangesien 'n metafoor alleen maar 'n eienskap van taal is en nie van die gedagte nie. 'n Metafoor het daarom nie regtig ' $n$ plek in die sentrum van linguistiek gekry nie en die bestudering daarvan is (verkeerdelik) aan literêre kritici oorgelaat.

Vanaf die einde van die sewentigerjare het navorsers soos Ortony (1979) en Lakoff en Johnson (1980) egter die kognitiewe wending in die metaforiek voltooi (Steen, 1994:3). Hierdie navorsers het die kognitiewe teorie van metafore (sien hierbo, 3.10) ontwikkel met die uitgangspunt dat 'n metafoor 'n plek in die diepste en mees algemene prosesse van menslike interaksie met die werklikheid het. 'n Metafoor is 'n duidelike voorbeeld van die mens se vermoë om sin van sy wêreld te maak. 'n Metafoor is die mees prominente wyse waarop die wêreld soos dit buite die waarnemer bestaan, ontdek en begryp word (Gunton, 1989:40). Die gevolg van hierdie wending is dat die stigma wat aan 'n metafoor gekleef het, verwyder is, maar ook dat die oënskynlik goed-gedefinieerde funksie van 'n metafoor in die retorika en poëtika herdefinieer moes word. Mac Cormac (1985), Kittay (1987), Steen (1994), Steen en Gibbs (1999), Gibbs (1999) en Steinhart (2001) is almal voorstanders van die kognitiewe beskouing van metafore.

$3 \quad$ Vir 'n voorbeeld van 'n metodiek voortvloeiend uit 'n metafoorteorie, sien 5.2.3 hieronder. 
Ek meen dat die verskuiwing na 'n kognitiewe metafoorteorie 'n welkome wending in die metaforiek gebring het. Ek stem met Steen (1994:11) saam dat die kognitiewe benadering nie die tradisionele benaderings wat gebaseer is op ooreenkoms, vergelyking en interaksie uitsluit nie. ' $n$ Metafoorteorie wat geskik is vir die ontleding van die metafore in die Nuwe Testament sal dus hierdie wending deeglik moet verdiskonteer (vgl. Liebenberg, 2001:77).

\subsection{Identifisering van metafore}

Dit is dikwels moeilik om te onderskei tussen metaforiese gebruik van 'n woord en bloot die vreemde of ongewone gebruik daarvan (Cooper, 1986:82). Dit is nie altyd duidelik of 'n persoon 'n metaforiese beskrywing gee of 'n beskrywing wat hy op grond van sy oortuigings as letterlik beskou nie. Daar is geen outomatiese en voor die hand liggende prosedure vir die identifisering van metafore nie. Die mees algemene benadering is dat ' $n$ mens ' $n$ metafoor herken deurdat daar een of ander anomalie is (Tourangeau, 1982:18). 'n Mens probeer die diskoerseenheid eers letterlik interpreteer, en as dit nie werk nie, word 'n metaforiese interpretasie probeer.

In die algemeen gesproke sou 'n mens verwag dat 'n spreker/outeur se diskoerseenheid informatief, geldig en relevant sal wees (Bouson, 1980:20). Indien die metafoor letterlik verstaan word, voldoen die meeste metafore nie aan hierdie tweede verwagting nie, naamlik dié van geldigheid. Voldoening aan hierdie verwagting is egter nie 'n voorvereiste vir 'n diskoerseenheid om as 'n metafoor getipeer te word nie. Wat wel waar is, is dat 'n diskoerseenheid nie in isolasie gesien moet word nie (Bouson, 1980:20). Die konteks sluit tyd, plek en omstandigheid van die uiting, die voorafgaande uitings, aannames oor die spreker/outeur se oortuigings en bedoelings en die verwagtings soos hierbo gestel in. Elke diskoerseenheid moet kontekstueel beoordeel word voordat dit as ' $n$ metafoor geïdentifiseer kan word. Selfs in die geval van diskoerseenhede wat ooglopend geen konteks het nie, identifiseer die hoorder/leser dit met 'n (vermeende) bekende konteks.

Die volgende faktore speel 'n bepalende rol in die vasstelling van die konteks: die aard van die sosiale handeling waaraan die deelnemers deelneem; wie die deelnemers is, hulle status, rolle en verhoudings met mekaar; en die retoriese doelwitte wat taal binne die konteks van die bepaalde sosiale handeling het (Goatly, 1997:283). Interaksie tussen metafore is ook moontlik en moet in ag geneem word (Goatly, 1997:255 e.v.). 
Uit die kognitiewe teorie oor metafore (sien hierbo) is dit duidelik dat die hoorder/leser van die linguistiese metafoor deur 'n kognitiewe proses by die konseptuele metafoor moet kom. Vyf stappe kan in hierdie proses geïdentifiseer word (Steen, 1999:57 e.v.):

- Die identifikasie van die fokus van die metafoor (Steen, 1999:60). Die fokus van die metafoor is maar een element van die metafoor as geheel en verwys na die linguistiese uitdrukking wat nieletterlik in die diskoerseenheid gebruik word (dus die strekking). Die onmiddellike linguistiese omgewing van die fokus van die metafoor is die raamwerk (frame) van die metafoor.

- Die identifikasie van die metaforiese idee (Steen, 1999:62). Die resultaat van stap twee is 'n metaforiese idee in die vorm van 'n proposisie met letterlike en nie-letterlike konsepte.

- Die bepaling van die vergelykende struktuur wat in die nieletterlike kartering tussen domeine vir elke konseptuele metafoor geïmpliseer word (Steen, 1999:66). Die rekonstruksie van die geïmpliseerde vergelyking is 'n kritiese stap in die verstaan van 'n metafoor.

- Die vul van die gapings in die vergelyking deur nie-letterlike analogie-identifikasie (Steen, 1999:68). Die fokus en medium van die metafoor vorm die begrensing vir hierdie stap. Dié twee elemente van die metafoor beïnvloed mekaar wedersyds wanneer die twee kante van die analogie geïdentifiseer word, naamlik die bron- en teikendomeine.

- Die identifikasie van die volledige nie-letterlike beeld (Steen, 1999:71). Dit geskied deur die invul van die konseptuele struktuur van die twee kante van die nie-letterlike analogie, naamlik die bron- en teikendomeine. Die resultaat is 'n konseptuele netwerk waaruit stelle ooreenstemmings afgelei kan word.

Volgens Kittay kan die volgende vereistes vir die bepaling van metaforiese uitings gestel word:

- Die veronderstelde spreker/outeur moet 'n bevoegde gebruiker van die taal wees, nie in die uiting 'n taalfout begaan nie en die saamwerkbeginsel ("co-operative principle") nakom. Die saamwerkbeginsel stel dat 'n deelnemer aan 'n gesprek nie meer of minder inligting gee as wat vereis word nie en dat die inligting waar, relevant en duidelik is (Kittay, 1987:83).

- Daar moet niks in die konteks wees om die hoorder/leser te oortuig dat die wêreld waarna die uiting verwys, substansieel van 
sý wêreld verskil of dat daar nie aan sy gewone verwagtings voldoen sal word nie.

- Die uiting moet, in sy konteks, 'n ongerymdheid in die diskoers vertoon of as metafories aangedui word.

'n Metafoorteorie wat geskik is vir die doeleindes van hierdie studie moet 'n werkbare werkwyse vir die identifisering van metafore bied. Ek meen dat Kittay (1987:91) se vereistes nuttige riglyne vir so 'n werkswyse bied.

\subsection{Die grammatika van metafore}

'n Uiting in 'n taal is enige sintaktiese korrekte volgorde van woorde uit die woordeskat van daardie taal (Steinhart, 2001:30). Tirrell (1991:346-347) onderskei ses grammatiese tipes waarin metafore gegiet word:

- Eenvoudige identiteite in die vorm "A is B".

- Suiwer predikasies in die vorm "A is F".

- Soortlike predikasies in die vorm "A is ' $\mathrm{K}$ ".

- Plaasvervangende metafore wat gevorm word deur die plaasvervanging van 'n term wat nie letterlik van toepassing is nie met een wat wel is.

- Naamwoordelike metafore in die vorm "die B van A".

- Werkwoordelike metafore in die vorm "A werkwoord B" waar die werkwoord nie letterlik deur A gedoen kan word nie of nie letterlik aan $B$ gedoen kan word nie.

Brooke-Rose (1958:24 e.v.) beskryf 'n soortgelyke indeling van bogenoemde grammatiese tipes met verwysing na metafore met naamwoorde, genitiewe metafore, metafore met werkwoorde en adjektiewe as metafore. Van der Watt (2000:21 e.v.) volg haar indeling. Ook die grammatika van metafore sal in 'n geskikte metafoorteorie verreken moet word.

\subsection{Metafore en die Bybel}

Die gebruik van metafore in die Skrif as kriterium vir die bepaling van ' $n$ geskikte metafoorteorie is van besondere belang, aangesien die voorwerp van hierdie studie 'n deel van die teks van die Bybel uitmaak. In navolging van die Verligting het die modernisme 'n skeiding tussen die rasionele en die verbeelding gebring: 
eersgenoemde is die pad na kennis en waarheid, en laasgenoemde die pad na onkunde en valsheid (Avis, 1999:22). Die postmodernisme het op hulle beurt die figuurlike onderwaardeer deur dit van die rasionele te skei en daarvan 'n minder belangrike doel op sigself gemaak (Avis, 1999:29). Die rasionele en verbeelding sluit mekaar eerder in as uit, omdat metafore die boublokke van denke is (Avis, 1999:22). Deur metafore skets die boeke van die Bybel 'n verbeeldingryke visie van God en sy handelinge met mense (Avis, 1999:65). Die rede hiervoor is tweërlei, naamlik dat dit die natuurlike modus van uitdrukking van antieke kulture was, en dit is ook die beste manier om die diepste lewenswaarhede te kommunikeer.

\section{Die keuse van 'n geskikte metafoorteorie vir die ontleding van metafore in die Nuwe Testament}

\subsection{Keuse en motivering}

My keuse val op Van der Watt (2000) se metafoorteorie en die meegaande metodiek. Van der Watt trek die elemente van doelmatigheid van die ander metafoorteorieë saam, en volg dit op met 'n werkbare metodiek wat spesifiek op die Nuwe Testament toegespits is. Ek meen dat sy teorie en metodiek aan die gestelde kriteria vir 'n geskikte metafoorteorie voldoen ten spyte van kritiek teen sommige aspekte daarvan (sien hieronder 5.2.2). Sy gevolgtrekkings oor metafore in die Nuwe Testament is na my oordeel geldig. Tog moet 'n mens in gedagte hou dat sy teorie spesifiek op die Evangelie volgens Johannes toegespits is, en die verwagting is dat dit op ander boeke van die Nuwe Testament toegepas kan word. Toepassings op ander metafore in die Nuwe Testament sal hierdie verwagting moet toets.

\subsection{Van der Watt se metafoorteorie}

'n Keuse van 'n geskikte metafoorteorie is gemaak en hierdie teorie word voorts in meer besonderhede beskryf en beoordeel.

\subsubsection{Terminologie}

As uitgangspunt stel Van der Watt (2000:1) dat 'n simbool in sy eenvoudigste sin enigiets is wat op iets anders buite homself dui of dit verteenwoordig. Die "iets anders" is gewoonlik iets wat konvensioneel daarmee geassosieer sal word, welke assosiasie dus op semantiese gronde berus. Daar hoef nie 'n ooglopende verband tussen die simbool en sy referent te wees nie; die simbool 
funksioneer eerder as sodanig op grond van konvensie. Alle ingeligte mense sal die simbool kan interpreteer. 'n Metafoor kan dus ' $n$ simbool word indien die onverenigbare verband van die oorspronklike metafoor deur semantiese konvensie gestabiliseer word. Dit gebeur wanneer die oorspronklike interaksie tussen medium en topiek nie meer funksioneer nie.

Die probleem met ' $n$ wye definisie van simboliek is dat die kriteria vir die klassifikasie van sekere figuurlike elemente dikwels ontbreek (Van der Watt, 2000:4). Van der Watt fokus juis op elemente wat op formeel tekstuele vlak as metafore geïdentifiseer kan word. Dit moet moontlik wees om 'n spesifieke woord, frase of beeld sintakties en semanties as 'n metafoor te identifiseer.

By verbale metafore verkies Van der Watt (2000:18) die onderskeid tussen fokus en raamwerk. Eersgenoemde verwys na die rede waarom die leser voel dat hy nie die sin letterlik kan verstaan nie, en laasgenoemde na die res van die $\sin .4$ By nominale metafore verkies Van der Watt (2000:18) egter die terme topiek (verwysende na die letterlike raamwerk) en medium (verwysende na die figuurlike gebruik van die woord) soos Richards (1936; sien hierbo 2) dit gebruik.

Beelding (imagery) is die algehele en koherente beskrywing of gedagteprentjie van objekte met ooreenstemmende handelinge en verbande wat deur assosiasie of tematies bymekaar hoort (Van der Watt, 2000:18). Enige aantal metafore, vergelykings of soortgelyke tipes frases kan dus in die beeld ingesluit word ten einde die hele prentjie te voltooi. Al die inligting in die beeld is egter nie ewe belangrik nie. Sodra die handelinge, verbande of objekte verander, volg ' $n$ nuwe beeld. ' $n$ Beeld kan as 'n beskrywing of metafoor bestaan. Wanneer dit as 'n metafoor gebruik word, is dit gelyktydig voorstelling en verteenwoordiging (Van der Watt, 2000:19). Dit roep 'n sekere beeld op (voorstelling, of presentation) maar gebruik ook die beeld om na iets anders te verwys (verteenwoordiging, of representation). 5

$4 \quad$ In die metafoor "The chairman plowed through the meeting" is "plowed" die fokus en "The chairman ... through the meeting" die raamwerk (Van der Watt, 2000:18).

Van der Watt (2000:19) gebruik Johannes 10:1-16 as voorbeeld. In verse 1-5 word 'n beeld wat met skaapboerdery verband hou, voorgestel. Maar in verse 716 word die voorgestelde beeld gebruik om die goddelike werklikheid van die Seun te verteenwoordig. 
In die Evangelie volgens Johannes word hierdie oorgang van voorstelling na verteenwoordiging met $\pi \alpha \rho \circ \mu^{\prime} \alpha^{6}$ aangedui. In die

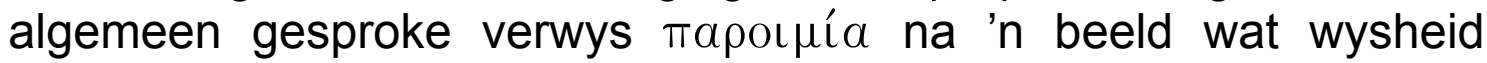
bevat en dikwels kripties gestel is. Deur die verstaan van die beeld word wysheid verkry. Dit verwys na al die spreuke van Jesus wat 'n spesiale perspektief vereis ten einde korrek verstaan te word (Van der Watt, 2000:160). Hierdie geestelike perspektief stel die hoorder/leser in staat om die verwysing na die geestelike

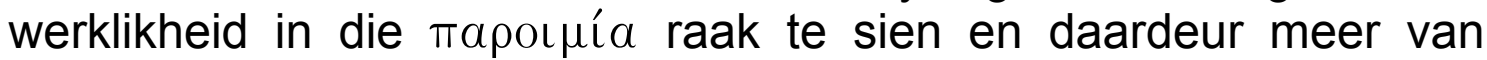
Jesus te verstaan.

\subsubsection{Grondslag van Van der Watt se teorie}

Van der Watt (2000:5) neem as uitgangspunt nie 'n uitgebreide metafoorteorie wat op 'n bepaalde literêre teorie gebou is en wat induktief as die interpretasiemodel van metafore (in sý geval in die Evangelie volgens Johannes) moet dien nie. Hy poog eerder om deur deeglike deduktiewe ondersoek vas te stel hoe Johannes die sentrale metafore in sy Evangelie gebruik en toepas. Dit word as raamwerk vir die lees van die res van die metafore in die Evangelie gebruik. Die fokus is op die funksionaliteit en dus die kommunikatiewe waarde van die metafore. Daarin word ooreenkomste gesoek wat tot 'n meer algemene formulering van Johannes se gebruik van metafore kan lei.

Van der Watt se stelling (2000:5) dat hy nie van 'n bepaalde metafoorteorie gebruik maak nie, moet krities beoordeel word. Enersyds blyk sekere aspekte van sy sogenaamde "minimum theory" (2000:5 e.v.) 'n teruggryp na die tradisionele beskouing van metafoor te wees. ' $n$ Voorbeeld hiervan is die stelling dat 'n metafoor tot stand kom wanneer die letterlike betekenis van die woord in 'n sin absurd, irrelevant of onwaar is, hoewel die sin nogtans 'n nuttige inhoud kan hê (Van der Watt, 2000:7). Die bevindings van kognitiewe linguistiek het egter tot gevolg dat gewone en uitsonderlike (of eienaardige) taal deur middel van dieselfde proses geïnterpreteer word (Liebenberg, 2001:80). Daar is dus geen basis vir Van der Watt se standpunt (2000:7; voetnoot 42) nie, naamlik dat metaforiese uitdrukkings reëls vir grammatikaal korrekte

Johannes 10:6: "Deur hierdie beeld het Jesus met hulle gepraat, maar hulle het nie verstaan wat dit was wat Hy vir hulle wou sê nie." (1983 Nuwe Afrikaanse

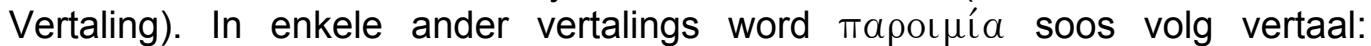
"gelykenis" in die Ou Afrikaanse Vertaling (1957), "parable" in die King James Version (1982) en "figure of speech" in die New International Version (1984). 
uitdrukkings verbreek. Metaforiese uitdrukkings is juis gewone taal. Verder dui Liebenberg (2001:84 e.v.) oortuigend aan dat die konvensionele onderskeid tussen letterlike en figuurlike betekenis in die lig van kognitiewe metafoorteorie onhoudbaar is. Tog is Van der Watt (2000:7) se gevolgtrekking dat onverenigbaarheid bloot 'n belangrike merker in die identifisering van metafore is. Soos aangedui in 4.2 hierbo is dit nie teenstrydig met die sienings van voorstanders van 'n kognitiewe metafoorteorie, soos Steen (1999) en Kittay (1987), nie.

Andersyds verwys Van der Watt (2000:13) met goedkeuring na die ontwikkeling in metafoorteorie, naamlik van die metafoor as 'n dekoratiewe taalverskynsel na die metafoor as 'n noodsaaklike element in kommunikasie. Hy verwys ook herhaaldelik na die terminologie eie aan kognitiewe metafoorteorie, byvoorbeeld kategorieë en konsepte (Van der Watt, 2000:22). Dit blyk dus dat Van der Watt se teorie inderdaad ' $n$ vermenging van bestaande teorieë as grondslag het. 'n Grondige belyning van sy teorie met die kognitiewe metafoorteorie sou egter na my mening gepas en noodsaaklik wees om die teenstrydighede uit te stryk, veral in die lig van die ontwikkeling in die kognitiewe wetenskap (sien byvoorbeeld Johnson, 1995).

Konteks speel 'n baie belangrike rol in die identifisering van metafore, aangesien 'n metafoor alleen binne sy konteks as metafoor funksioneer (Van der Watt, 2000:11-12). 'n Woord mag in een konteks metafories gebruik word, maar in 'n ander letterlik. Die konteks bepaal ook realistiese grense vir die interpretasie en gebruik van 'n metafoor. Die voortgesette kognitiewe en emotiewe funksionering van 'n metafoor is afhanklik van die sosio-historiese raamwerk waarbinne die metafoor oorspronklik geskep is (Van der Watt, 2000:12). Daarsonder is dit onmoontlik om die intensiteit, bedoeling en betekenis van 'n metafoor, veral in antieke tekste, vas te stel.

Van der Watt (2000:14 e.v.) onderskei drie tipes metafore, naamlik metafore met plaasvervanging as basis, metafore met vergelyking as basis en metafore met interaksie as basis. Metafore van plaasvervanging beteken dat woorde op die figuurlike vlak van betekenis met woorde op die letterlike vlak vervang word (Van der Watt, 2000:111). Dit mag ook personifikasie insluit wat die oordrag van sekere eienskappe tussen die woorde op die twee vlakke moontlik maak. Die graad of omvang van oordrag wissel van situasie tot situasie en word deur die konteks as geheel bepaal. Dit 
kan selfs wederkerig wees. Die ontdekking van die vervangende woord verskaf die sleutel tot die verstaan van die metafoor.

Metafore van vergelyking is streng gesproke nie metafore nie, maar eerder vergelykings (Van der Watt, 2000:116). 'n Vergelyking stel die punt van vergelyking duidelik en is daarom meer spesifiek as 'n metafoor. Deur vergelyking word twee situasies gelyk gestel. Gelees saam met metafore dui vergelykings die sentrale punte van die figuurlike kommunikasie aan. So word die verskillende aspekte van die beeldspraak in toepaslike funksionele en relasionele perspektief tot mekaar gestel.

Metafore van interaksie steun sterk op analogiese interaksie en word gewoonlik in verbale metafore teëgekom (Van der Watt, 2000:114). Die objekte word vervang ten einde die twee letterlike en figuurlike vlakke te onderskei, maar dieselfde werkwoord is van toepassing op albei vlakke. Metafore van plaasvervanging en interaksie word gewoonlik in kombinasie gebruik, aangesien die interaksie nie moontlik sou wees as die twee werklikhede nie deur plaasvervanging met mekaar geassosieer word nie. Die werkwoord dui die punt van analogie en die betekenisverandering of -oordrag aan. Die analogie dui op sy beurt weer terselfdertyd die punt van ooreenkoms en die punt van verskil aan. So ontstaan nuwe betekenisse. Analogie is die geïdentifiseerde ooreenkoms tussen die fokus en raamwerk (of topiek en medium) van 'n metafoor wat gelyktydig die verskil tussen die twee bevat en uitdruk (Van der Watt, 2000:20). Die twee metaforiese elemente is dus nie gelyk aan mekaar nie, maar eerder analogies. In die punt van ooreenstemming word ' $n$ belangrike punt van verskil ook gevind as gevolg van die nie-ooreenstemmende aard van die metafoor (Van der Watt, 2000:42).

Van der Watt (2000:157) beskryf sy teorie as 'n metafoorteorie vir minstens 'n spesifieke antieke dokument. In hoeverre dit vir ander antieke dokumente geldig is, sal deur die resultate van verdere navorsing aangedui word. Tog vorm dit deel van die gebruik van metafore in antieke dokumente in die algemeen.

\subsubsection{Metodiek}

Van der Watt (2000:25 e.v.) volg 'n deskriptiewe benadering tot die metafore in die Evangelie volgens Johannes. Hy meen dat vorige evaluerings en interpretasies van die beeldspraak in die Evangelie nie die beperkings wat deur die teks self gestel word, in ag geneem het nie. Daarom fokus hy op die wyse waarop Johannes self die 
sentrale metafore in die Evangelie geformuleer en toegepas het, en die daaruit voortspruitende funksionele dinamiek. Die metodiek behels die volgende stappe:

- Eerstens is dit van belang dat die interpreteerder voldoende kennis het van die objekte waarna in die metafoor verwys word (Van der Watt, 2000:26). Die interpreteerder moet veral bedag wees op watter elemente van daardie objekte figuurlik gebruik word en watter nie. Dit verhoed dat meer van sekere elemente gemaak word wat nie deur die skrywer beklemtoon word nie. Die teks is dus die interpreteerder se gids.

- Tweedens word metaforiese taal geïdentifiseer aan die hand van die onverenigbaarheid tussen die elemente daarvan (Van der Watt, 2000:30).

- In die derde plek word die metaforiese taal ontleed in terme van verwantskappe op grammatiese, sintaktiese, semantiese en kontekstuele vlak (Van der Watt, 2000:31 e.v.).

- Verder word die simboliese gebruik van die beeldspraak in die Skrif ondersoek (Van der Watt, 2000:51).

- In die vyfde plek word die genre van die teksgedeelte bepaal, asook die bydrae wat die metafoor daartoe lewer (Van der Watt, 2000:54).

\subsubsection{Enkele gevolgtrekkings oor metafore}

Op grond van die ontleding van die sentrale metafore in die Evangelie volgens Johannes, kom Van der Watt (2000) tot die volgende gevolgtrekkings oor metafore:

- 'n Lewende metafoor moet 'n nuwe betekenis vinnig en effektief ontlok, met 'n element van die onverwagte (Van der Watt, 2000:118).

- Metafore moet so kort as moontlik wees.

- Soms word narratief gebruik om agtergrondsinligting vir die ontwikkeling van die metafore binne die beeldspraak te verskaf (Van der Watt, 2000:122).

- Kohesie is die sement waarmee verskillende metaforiese uitdrukkings saamgesnoer word om 'n meer komplekse kommunikatiewe eenheid te vorm (Van der Watt, 2000:123 e.v.). Kohesie word aangedui deur tematies verwante woord- of teksverbande; herhaling van dele van die beeldspraak; stilistiese 
kenmerke soos parallelismes of chiasmes; linguistiese kenmerke soos sintaktiese of semantiese merkers; en suggestie deur byvoorbeeld dubbelsinnige stellings.

- 'n Metafoor is in wese 'n oop kommunikasiekanaal, maar dit word deur die konteks begrens (Van der Watt, 2000:139).

- Metafore moet binne die werklikheid waarbinne hulle ontstaan, funksioneer, en nie in allegorieë ontaard nie (Van der Watt, 2000:142).

- Die boodskap het altyd prioriteit bo die beeld (Van der Watt, 2000:143). Die beeld bly bloot die boodskapper. Die formele struktuur van die beeld kan nie gebruik word as basis vir die bepaling van belangrike teologiese waarhede nie.

- Metafore word gebruik om geestelike waarhede oor te dra (Van der Watt, 2000:149). Hierdie waarhede is nie van 'n laer orde as letterlike stellings nie.

Myns insiens is Van der Watt se gevolgtrekkings oor metafore sonder uitsondering op die metafore in die Nuwe Testament van toepassing. Hierdie gevolgtrekkings sal in die ontleding van NuweTestamentiese metafore verreken moet word.

\section{Gevolgtrekking}

Die doel van hierdie artikel is om 'n geskikte metafoorteorie te vind ten einde die metafore in die Nuwe Testament te ontleed. Uit die uiteensetting van verskillende metafoorteorieë en die kriteria vir 'n geskikte metafoorteorie vir die ontleding van metafore in die Nuwe Testament, het dit geblyk dat Van der Watt se metafoorteorie by uitstek vir dié doel geskik is. Van der Watt se voorgestelde metodiek blyk gemaklik integreerbaar in 'n grammaties-historiese eksegetiese benadering te wees. ${ }^{7}$ Sy teorie voldoen bowenal aan die vereiste dat dit geskik moet wees vir toepassing op die Nuwe Testament as unieke dokument. Deur Van der Watt se metafoorteorie op die metafore van die Nuwe Testament toe te pas, sal die eksegeet die aard van metafore en die bydrae wat dit tot die oordra van die boodskap lewer, deeglik verreken.

$7 \quad$ Vir 'n voorbeeld hoe die gekose metafoorteorie gemaklik binne 'n grammatieshistoriese eksegetiese benadering toegepas kan word, vergelyk Goede (2004). 


\section{Geraadpleegde bronne}

AVIS, P.D.L. 1999. God and the creative imagination: metaphor, symbol and myth in religion and theology. London: Routledge.

BOUSON, R. 1980. Metaphor and simile. Chicago: University of Illinois. (Ph.D. thesis.)

BROOKE-ROSE, C. 1958. A grammar of metaphor. London: Secker \& Warburg.

COOPER, D.E. 1986. Metaphor. Oxford: Blackwell.

GIBBS, R.W. 1999. Taking metaphor out of our heads and putting it into the cultural world. (In Gibbs, R.W. \& Steen, G.J., eds. Metaphor in cognitive linguistics: selected papers from the fifth International Cognitive Linguistics Conference, Amsterdam, July 1997. Amsterdam: Benjamins. p. 145-166.)

GOATLY, A. 1997. The language of metaphors. London: Routledge.

GOEDE, H. 2004. Die "swakste lede" in Paulus se liggaam-metafoor: 'n grammaties-historiese studie. Potchefstroom: Noordwes-Universiteit. (M.A.-verhandeling.)

GUNTON, C.E. 1989. The actuality of atonement: a study of metaphor, rationality and the Christian tradition. Grand Rapids: Eerdmans.

INDURKHYA, B. 1994. Metaphor as change of representation: an interaction theory of cognition and metaphor. (In Hintikka, J., ed. Aspects of metaphor. Dordrecht: Kluwer Academic. p. 95-150.)

JOHNSON, M. 1995. Introduction: Why metaphor matters to philosophy. Metaphor and symbolic activity, 10(3):157-162.

KITTAY, E.F. 1987. Metaphor: its cognitive force and linguistic structure. Oxford: Clarendon.

LAKOFF, G. \& JOHNSON, M. 1980. Metaphors we live by. Chicago: University of Chicago Press.

LAKOFF, G. \& JOHNSON, M. 2002. Why cognitive linguistics requires embodied realism. Cognitive linguistics, 13(3):245-263.

LAKOFF, G. \& TURNER, M. 1989. More than cool reason: A field guide to poetic metaphor. Chicago: University of Chicago Press.

LIEBENBERG, J. 2001. The language of the kingdom and Jesus: parable, aphorism, and metaphor in the sayings material common to the synoptic tradition and the Gospel of Thomas. Berlin: De Gruyter.

MAC CORMAC, E.R. 1985. A cognitive theory of metaphor. Cambridge: MIT.

ORTONY, A., ed. 1979. Metaphor and thought. Cambridge: Cambridge University Press.

RICHARDS, I.A. 1936. The philosophy of rhetoric. New York: Oxford University Press.

STANFORD, W.B. 1936. Greek metaphor: studies in theory and practice. Oxford: Blackwell.

STEEN, G.J. 1994. Understanding metaphor in literature: an empirical approach. London: Longman.

STEEN, G.J. 1999. From linguistic to conceptual metaphor in five steps. (In Gibbs, R.W. \& Steen, G.J., eds. Metaphor in cognitive linguistics: selected papers from the fifth International Cognitive Linguistics Conference, Amsterdam, July 1997. Amsterdam: Benjamins. p. 57-77.) 
STEEN, G.J. \& GIBBS, R.W. 1999. Introduction. (In Gibbs, R.W. \& Steen, G.J., eds. Metaphor in cognitive linguistics: selected papers from the fifth International Cognitive Linguistics Conference, Amsterdam, July 1997. Amsterdam: Benjamins. p. 1-8.)

STEINHART, E. 2001. The logic of metaphor: analogous parts of possible worlds. Dordrecht: Kluwer Academic.

STEINHART, E. \& KITTAY, E.F. 1994. Generating metaphors from networks: a formal interpretation of the semantic field theory in metaphor. (In Hintikka, J., ed. Aspects of metaphor. Dordrecht: Kluwer Academic. p. 41-94.)

TIRRELL, L. 1991. Reductive and nonreductive simile theories of metaphor. Journal of philosophy, 88(7):337-358.

TOURANGEAU, R. 1982. Metaphor and cognitive structure. (In Miall, D.S., ed. Metaphor: problems and perspectives. Brighton: Harvester. p. 14-35.)

VAN DER WATT, J.G. 2000. Family of the King: dynamics of metaphor in the Gospel according to John. Leiden: Brill.

\section{Kernbegrippe:}

grammaties-historiese benadering

metafoor

metafoorteorie

Nuwe Testament

Key concepts:

grammatico-historical approach

metaphor

New Testament

theory of metaphor 
